\title{
Modulation of Immune Cell Subsets by Hepatitis C Virus and Antiviral Therapy in Early Virological Response HCV Genotype 4-Infected Patients with Compensated Liver Disease
}

\author{
Sahar Essa $^{a}$ Raja'a Al-Attiyah ${ }^{a}$ Iqbal Siddique ${ }^{\text {b, c }}$ Widad Al-Nakib ${ }^{a}$

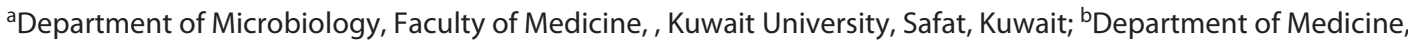 \\ Faculty of Medicine, Kuwait University, Safat, Kuwait; 'Thunayan Al-Ghanim Gastroenterology Center, Al-Amiri \\ Hospital, Safat, Kuwait
}

\section{Highlights of the Study}

- This study shows that chronic hepatitis C virus (HCV) infection is associated with immunomodulation of immune cell subsets.

- Immunomodulation of immune cell subsets by pegylated interferon- $\alpha$ and ribavirin (PegIFN/RBV) therapy is essential for generating an efficient immune response to eliminate HCV infection.

- PegIFN/RBV therapy facilitates the enhancement of cytotoxic T cells and natural killer/T cells and the reduction in $\mathrm{B}$ cells, activated T cells, and T regulatory cells.

\section{Keywords}

Immunophenotyping $\cdot$ Immune cell subsets $\cdot$ Hepatitis C virus

\section{Abstract \\ Background: Resolution of chronic hepatitis C virus (HCV) infection requires a complicated interaction between im- mune cell subsets. The effect of antiviral therapy on immune cell subsets remains to be defined. This study aimed to in- vestigate the absolute count of certain immune cell subsets during therapy with pegylated interferon-a and ribavirin (PegIFN/RBV). Materials and Methods: Sixty HCV genotype 4-infected patients with compensated liver disease were treated with PegIFN/RBV therapy for 52 weeks. Efficacy was measured by studying the early virological response (EVR) at post-therapy week 12 . Absolute counts of mature T cells, Thelper cells, T cytotoxic cells, activated T cells, natural kill-}

karger@karger.com www.karger.com/mpp

Karger $\frac{1}{\%}$

GOPEN ACCESS
(C) 2020 The Author(s)

Published by S. Karger AG, Basel

This is an Open Access article licensed under the Creative Commons Attribution-NonCommercial-4.0 International License (CC BY-NC) (http://www.karger.com/Services/OpenAccessLicense), applicable to the online version of the article only. Usage and distribution for commercial purposes requires written permission. er cells, natural killer/T (NKT) cells, B cells, and T regulatory cells (Treg), and the ratio of T helper to T cytotoxic cells were longitudinally analyzed by flow cytometry throughout the treatment and follow-up course. Results: Of the 60 genotype 4-infected subjects, 39 (65\%) had EVR and 21 (35\%) were non-EVR patients. In the first part of this study, there were significantly lower mean absolute count values of mature T, T cytotoxic, B, and NKT cells. Also, we detected statistically significantly lower mean values for the percentages of T cytotoxic, NKT, Treg, and activated T cells of HCV-infected patients at baseline values when compared with healthy subjects. After the initiation of PegIFN/RBV therapy, frequencies of T helper cells, activated T cells, Treg cells, B cells, and $T$ helper:T cytotoxic ratio were found to be significantly lower in EVR patients than in non-EVR patients $(p<0.05)$. In contrast, frequencies of T cytotoxic and NKT cells were significantly increased in EVR patients when compared to nonEVR patients $(p<0.05)$. Conclusion: These results suggest a 
pattern of higher levels of T cytotoxic and NKT cells, and lower levels of T helper, activated T, Treg, and B cell populations in patients who respond favorably to PegIFN/RBV therapy.

(c) 2020 The Author(s)

Published by S. Karger AG, Basel

\section{Introduction}

Hepatitis $\mathrm{C}$ virus (HCV) has significant capability to establish chronicity, as $70-80 \%$ of infected individuals fail to clear the virus and develop chronic hepatitis $\mathrm{C}$ infection. Complex host-virus interactions largely determine the clinical outcomes of HCV infection, ranging from resolution to chronic viral infection [1]. Impairment of T cell responses appears to be the major cause for failure to clear $\mathrm{HCV}$ in infected individuals [2-4]. HCV-specific T cell responses are essential elements in controlling HCV infection. Acute HCV infection associated with resolution of the infection is accompanied by strong, broad, and sustained $\mathrm{CD}^{+}$and $\mathrm{CD} 8^{+} \mathrm{T}$ cell responses, whereas chronic infections are characterized by weak, transient responses [2-4].

Several immune cell subsets play important roles in the pathogenesis, progression, and treatment outcomes of HCV infection [1-4]. Previous studies documented a strong and long-lasting $\mathrm{HCV}$-specific $\mathrm{CD}^{+} \mathrm{T}$ cell response after pegylated interferon- $\alpha$ and ribavirin (PegIFN/RBV) therapy in chronically $\mathrm{HCV}$-infected patients [5]. Others suggested a strong association with the induction, expansion, and/or recirculation of HCV-specific $\mathrm{T}$ cytotoxic cells after IFN therapy in chronically $\mathrm{HCV}$-infected patients and clearance of HCV infection [6]. Moreover, persistence of HCV infection has been associated with a partial stimulation of B lymphocytes [7]. A sustained response to PegIFN/RBV therapy has been reported to be associated with increased levels and/or activation of natural killer (NK) and natural killer/T (NKT) cells [8].

One of the critical factors contributing to the dysfunctional $\mathrm{T}$ cell immune responses during HCV infection includes active suppression by T regulatory cells (Treg) due to high viral load [9]. Previous studies have identified an increase in the proportions of Treg cells in peripheral blood and liver of chronically $\mathrm{HCV}$-infected patients [10]. PegIFN/RBV used to be the standard of care therapy for chronic HCV infection for several years [9], and PegIFN/RBV therapy has been shown result in a decline in Treg cells with fractional recovery of the damaged immune response $[10,11]$.

Immune Cell Subsets in Chronic HCV Patients
Screening of multiple cellular markers of peripheral blood leukocytes may help us understand the immunopathogenesis of the disease and predict responses to PegIFN/RBV. We hypothesized that the changes in absolute counts of immune cell subsets associate with viral load decline following PegIFN/RBV therapy and participate in the resolution of HCV infection in chronically infected patients. To test this hypothesis, we studied the absolute counts of peripheral mature T cells, T helper cells, T cytotoxic cells, B cells, NK cells, NKT cells, Treg cells, and activated $T$ cells to ascertain the relationship between absolute count changes and effectiveness of PegIFN/RBV therapy in patients with early virological response (EVR).

\section{Materials and Methods}

\section{Patients and Treatment}

The sample size obtained by statistical power analysis is 65 subjects, assuming a 95\% rate of change of HCV infection, $95 \%$ confidence interval, and 0.05 as the maximum accepted error. A total of 67 patients with chronic HCV infection and aged 21 years and above were recruited for this study. Patients were either hospitalized or presented for follow-up examination in AlAmiri Hospital, Kuwait, from October 2014 to September 2017. The baseline clinical data of recruited subjects are given in Table 1. A diagnosis of chronic hepatitis was made if the following criteria were present after follow-up for 26 weeks: significant and persistent symptoms, fluctuating or persistently elevated alanine aminotransferase and aspartate aminotransferase ( $>1.5$ fold of normal levels), normal serum albumin and prothrombin time, and ultrasonography revealing an enlarged bright texture of liver portal tract thickening and normal spleen. Patients with a history of hepatotoxic drug intake (amoxicillin-clavulanate, flucloxacillin, erythromycin, diclofenac, sulfamethoxazole/trimethoprim, isoniazid, disulfiram, ibuprofen, and flutamide), alcohol intake, and previous antiviral, immunomodulatory, or IFN therapy or those who were coinfected with hepatitis B virus or HIV were excluded from the study. The PegIFN/RBV therapy protocol consisted of $180 \mu \mathrm{g}$ of pegylated IFN- $\alpha$ (Pegasys ${ }^{\circledR}$; Roche, Germany) given subcutaneously once a week plus ribavirin 1,000-1,200 mg/day orally (adjusted to body weight, RBV dose $/ \mathrm{kg}=15 \mathrm{mg} / \mathrm{kg}$ orally per day in 2 divided doses). All patients received PegIFN/RBV therapy for 12 weeks. Patients who achieved $\mathrm{a} \geq 2 \log$ reduction of HCV RNA at week 12 of PegIFN/ $\mathrm{RBV}$ therapy compared to baseline level by a quantitative $\mathrm{HCV}$ RNA assay were classified as having achieved EVR. Patients who did not achieve a $\geq 2 \log$ reduction of HCV-RNA after week 12 of PegIFN/RBV therapy were classified as non-EVR [12]. Written informed consent was obtained from all participants. The study protocol was approved by the Ethics Committee of the Health Science Center, Kuwait University, and the Ministry of Health, Kuwait. Blood samples were collected on 5 occasions from all patients: at baseline and at 4, 13, 26, and 52 weeks after the initiation of PegIFN/RBV therapy. Thirty healthy subjects matched for sex ratio and mean age with the patient group were included as healthy controls (HC).

Med Princ Pract 2021;30:168-177 169 
Table 1. Demographic and clinical characteristics of subject groups

\begin{tabular}{llcc}
\hline Parameters & HC & EVR patients & Non-EVR patients \\
\hline$N$ & 30 & 46 & 21 \\
Sex (males/females) & $9 / 21$ & $26 / 20$ & $13 / 8$ \\
Age, years \pm SD & $29 \pm 4.2$ & $30 \pm 5.4$ & $32 \pm 7.4$ \\
ALT level, U/L \pm SD & $22 \pm 7.55$ & $78 \pm 34.55$ & $68 \pm 14.61$ \\
At week 12 & na & $36 \pm 14.76$ & $52 \pm 18.40$ \\
AST level, U/L $\pm S D$ & $18 \pm 10.5$ & $72.5 \pm 33.2$ & $79.5 \pm 44.2$ \\
At week 12 & na & $35 \pm 12.1$ & $61 \pm 29.3$ \\
HCV RNA level, $\log _{10}$ copies/mL $\pm S D$ & na & $5.94 \pm 0.53$ & $6.24 \pm 0.46$ \\
At week 12 & na & $1.54 \pm 0.65$ & $5.8 \pm 0.83$ \\
HCV genotype $(4 / 3 / 1)$ & na & $39 / 4 / 3$ & $21 / 0 / 0$ \\
\hline
\end{tabular}

Data are shown as mean $\pm \mathrm{SD}$. HC, healthy control; SD, standard deviation; HCV, hepatitis c virus; EVR, early virological response; na, not applicable; ALT, alanine aminotransferase; AST, aspartate aminotransferase.

\section{Biochemical and Virological Investigations}

Serum biochemical investigations (including bilirubin, albumin, alanine aminotransferase, aspartate aminotransferase, creatine, creatine kinase, and BUN) were measured on an automatic analyzer (Hitachi 7170A; Hitachi Ltd, Tokyo, Japan). Anti-HCV antibody levels were determined using the Architect anti-HCV assay (Abbott Diagnostics, Wiesbaden, Germany). Serum HCV RNA was quantified before the initiation of PegIFN/RBV therapy and at 4, 13, 26 and 52 weeks using a commercial real-time PCR kit (Roche Molecular Systems, Inc., Branchburg, NJ, USA). Genotyping of HCV was performed using a second-generation line probe assay (Inno-Lipa II; Innogenetics, Zwijndrecht, Belgium).

\section{Immunophenotyping by Flow Cytometry}

Blood samples were collected in EDTA tubes and processed within $2 \mathrm{~h}$ of collection. $100 \mu \mathrm{L}$ of blood was mixed with $10 \mu \mathrm{L}$ of the CYTO-STAT tetraCHROME CD45-FITC/CD4-RD1/CD8ECD/CD3-PC5 and CYTO-STAT tetraCHROME CD45-FITC/ CD56-RD1/CD19-ECD/CD3-PC5 murine monoclonal antibody mixtures (Beckman Coulter, USA). These antibody mixtures allowed for the simultaneous identification and enumeration of $\mathrm{T}$ cell $\left(\right.$ total $\left.\mathrm{CD}^{+}\right)$, $\mathrm{T}$ helper cell $\left(\mathrm{CD}^{+} \mathrm{CD} 4^{+}\right)$, $\mathrm{T}$ cytotoxic cell $\left(\mathrm{CD}^{+}{ }^{+} \mathrm{CD} 8^{+}\right)$, B cell $\left(\mathrm{CD} 19^{+}\right)$, NK cell $\left(\mathrm{CD} 3^{-} \mathrm{CD} 56^{+} \mathrm{CD} 16^{+}\right)$, and NKT cell $\left(\mathrm{CD}^{+} \mathrm{CD}^{2} 6^{+} \mathrm{CD} 16^{+}\right)$lymphocyte populations. The tubes were incubated in the dark for $10 \mathrm{~min}$ at room temperature after which lysis of red blood cells and stabilization and fixation of the stained cells were carried out through the addition of Immunoprep kit reagents (Beckman Coulter, Brea, CA, USA). The staining of Treg $\left(\mathrm{CD} 4^{+} \mathrm{CD} 25^{+}\right)$cells and activated $\mathrm{CD} 8^{+} \mathrm{T}$ cells was performed by incubating $100 \mu \mathrm{L}$ of blood with $10 \mu \mathrm{L}$ of a mixture containing anti-CD4-FITC and anti-CD25-PE, or anti-CD8-FITC and anti-CD26-PE antibodies (Beckman Coulter, USA). The tubes were incubated at room temperature in the dark for $15 \mathrm{~min}$, which was followed by the addition of Immunoprep reagents (Beckman Coulter, USA). This facilitated the measurement of the percentage of $\mathrm{CD} 25^{+}$among $\mathrm{CD} 4^{+} \mathrm{T}$ cells and the percentage of $\mathrm{CD} 26^{+}$marker among CD8 ${ }^{+} \mathrm{T}$ cells. Analysis of the lymphocyte subsets was made using an FC500 Flow Cytometer (15 mW) (Beckman Coulter Electronics, USA). The values were determined as percentages of all the parameters. Absolute values of the lymphocyte subsets (the number of cell $/ \mu \mathrm{L}$ ) were determined via the addition of flow count fluorospheres to the stained blood. A fluorescence gating strategy using $\mathrm{CD} 45^{+}$versus side scatter was carried out. Internal quality assurance was performed using optical alignment beads and IMMUNO-TROL control cells, and compensation reagents were used to eliminate bleed through fluorescence. Data analysis was performed using Coulter tetraONE SYSTEM software and System II software.

\section{Statistical Analysis}

Data management, analysis, and graphical presentation were carried out using the computer software "Statistical Package for Social Sciences, SPSS version 24.0" (IBM Corp., Armonk, NY, USA). The descriptive statistics for all the quantitative clinical variables are presented as mean \pm standard deviation (SD). General Linear Model was applied for repeated measures to test the main effects within and between follow-up weeks, as well as for EVR and non-EVR. The non-parametric Wilcoxon signed rank test was used to compare volume levels between different follow-up periods, and the Kolmogorov-Smirnov test for comparison between EVR and non-EVR. The Pearson correlation tests were performed for correlation analysis. The 2 -tailed probability value $p<0.05$ was considered statistically significant.

\section{Results}

\section{Baseline Patient Characteristics}

Out of the total number of $\mathrm{HCV}$-infected patients tested $(n=67)$, the majority of those patients $(n=60,89 \%)$ had genotype-4; thus, the statistical analysis was possible only for patients with genotype-4 (Table 1 ). The data of immune cell subsets for patients with other genotypes (1 and 3 ) could not be statistically evaluated because of the small numbers. 


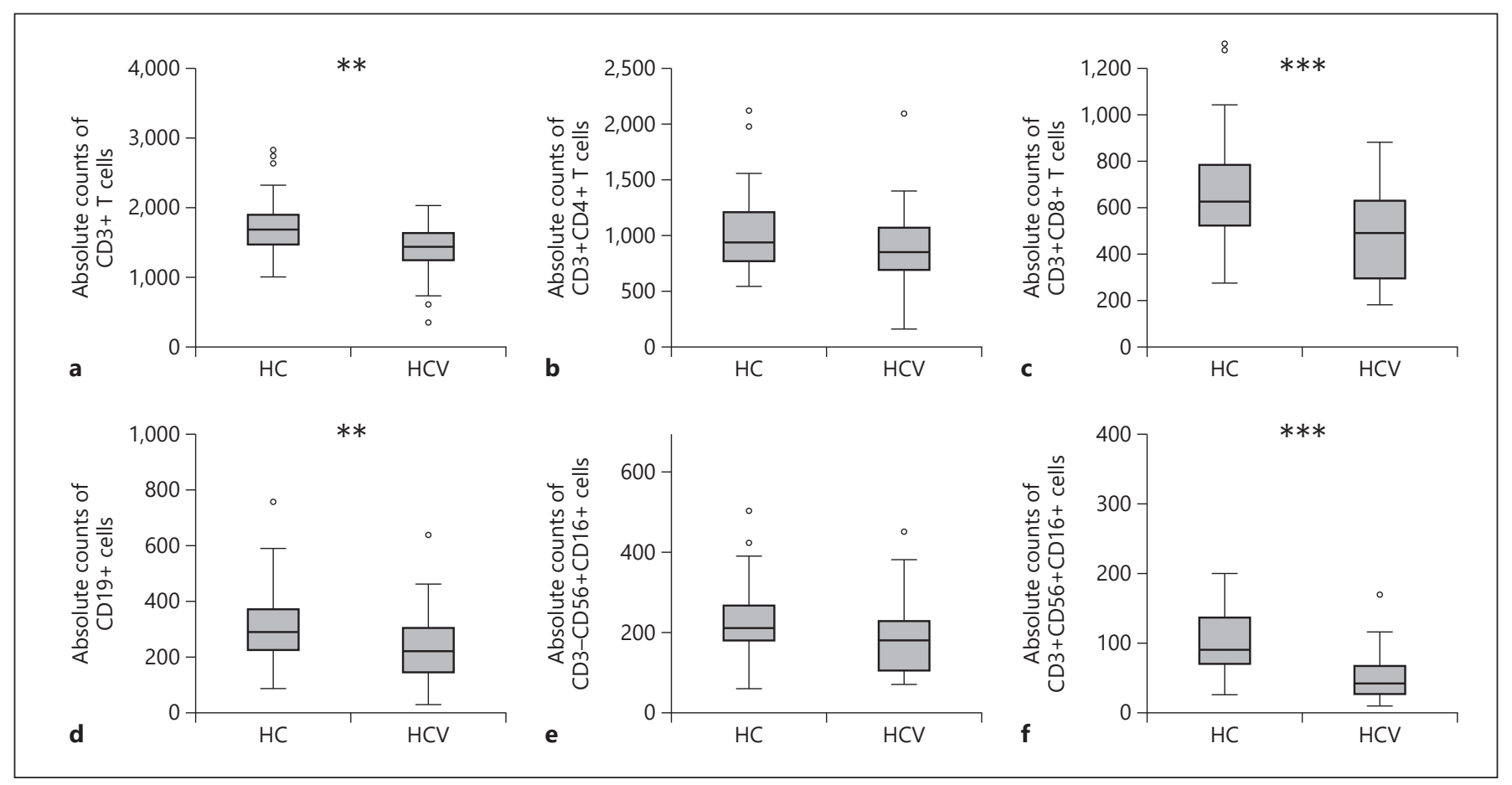

Fig. 1. Boxplots of interquartile range for absolute counts of cellular subsets in HCV-infected patients and HC. Mature T cells (a), T helper cells (b), T cytotoxic cells (c), B cells (d), NK cells (e), and NKT cells (f) at baseline values. ${ }^{*} p<0.05,{ }^{* *} p<0.01,{ }^{* * *} p<0.001$ refer to the statistical differences. HCV, hepatitis $\mathrm{C}$ virus; HC, healthy control; NK, natural killer; NKT, natural killer/T.

\section{Immune Cell Subsets in Untreated HCV-Infected Patients and Healthy Subjects}

There were significantly lower mean absolute count values of mature $\mathrm{T}$ cells (Fig. $1 \mathrm{a}, p<0.01$ ), $\mathrm{T}$ cytotoxic cells (Fig. 1c, $p<0.001$ ), B cells (Fig. 1d, $p<0.01$ ), and NKT cells (Fig. 1f, $p<0.001$ ) detected in the peripheral blood of HCV-infected patients at baseline values when compared with HC. Despite the lower mean absolute count values of NK cells and T helper cells of HCV-infected patients, no statistically significant differences were detected when compared with HC (Fig. 1b, e, $p>$ $0.05)$. We further analyzed the percentages of mature $T$ cell, T helper cell, T cytotoxic cell, B cell, NK cell, NKT cell, Tregcell $\left(\mathrm{CD} 4^{+} \mathrm{CD} 25^{+}\right)$, activated Tcell $\left(\mathrm{CD} 8^{+} \mathrm{CD} 26^{+}\right)$, and the ratio of $\mathrm{T}$ helper cell to $\mathrm{T}$ cytotoxic cell $\left(\mathrm{CD}^{+}: \mathrm{CD}^{+}\right)$populations of the $\mathrm{HCV}$-infected patients compared to HC (Fig. 2). Statistically significant lower mean values were detected for the percentages of T cytotoxic cells (Fig. $2 \mathrm{c}, p<0.05$ ), NKT cells (Fig. 2f, $p<0.001$ ), Treg cells (Fig. 2g, $p<0.001$ ), and activated T cells (Fig. $2 \mathrm{~h}$, $p<0.01)$ for HCV-infected patients when compared with HC. However, there were no statistically significant dif- ferences in the mean values for percentages of mature $\mathrm{T}$ cells (Fig. 2a), T helper cells (Fig. 2b), B cells (Fig. 2d), NK cells (Fig. 2e) and $\mathrm{T}$ helper cells: $\mathrm{T}$ cytotoxic cells ratio (Fig. 2i) in $\mathrm{HCV}$-infected patients when compared with $\mathrm{HC}(p>0.05)$.

Correlation between Absolute Counts and Percentages of Immune Cell Subsets and HCV RNA Levels in EVR

\section{Patients}

The relationship between the absolute counts and/or the percentages of various immune cell subsets with the HCV replication (represented by HCV RNA levels) was investigated in the EVR patients at baseline and at 4, 13, 26, and 52 weeks after the initiation of the PegIFN/RBV therapy. The percentages of B cells after 4 weeks of PegIFN/RBV therapy revealed a positive correlation with HCV RNA levels $\left(R^{2}\right.$ linear $\left.=0.06, p=0.04\right)$ (data not shown). A negative correlation was demonstrated between the percentages of Treg cells and HCV RNA levels at baseline values $\left(R^{2}\right.$ linear $\left.=0.116, p=0.02\right)$. Such a correlation was not detected after treatment. Other immune cell subsets did not show any correlation with HCV RNA 

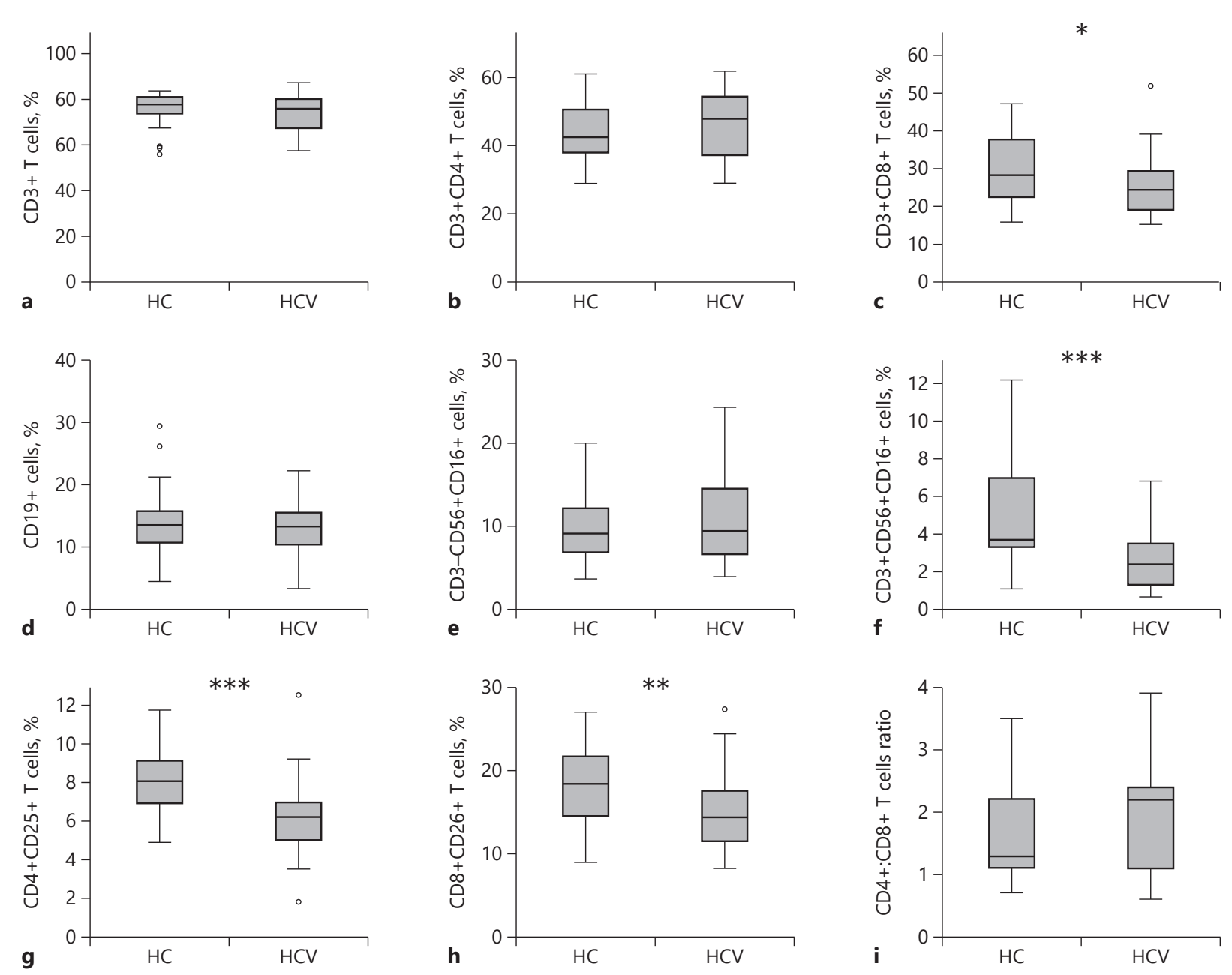

Fig. 2. Boxplots of interquartile range for percentages of immune cell subsets in HCV-infected patients and HC. Mature T cells (a), T helper cells (b), T cytotoxic cells (c), B cells (d), NK cells (e), NKT cells (f), Treg cells (g), activated T cells $(\mathbf{h})$, and $\mathrm{CD} 4^{+}: \mathrm{CD}^{+}$ratio (i) at baseline values. ${ }^{*} p<0.05,{ }^{* *} p<0.01,{ }^{* * *} p<0.001$ refer to the statistical differences. HCV, hepatitis C virus; HC, healthy control; NK, natural killer; NKT, natural killer/T; Treg, T regulatory.

levels after the initiation of PegIFN/RBV therapy in the EVR patients ( $p>0.05$, data not shown).

\section{Effect of PegIFN/RBV Therapy on Absolute Counts} and Percentages of Immune Cell Subsets in $\mathrm{HCV}$ -

Infected Patients (EVR vs. Non-EVR)

Data for the immunophenotyping of immune cell subsets for the genotype-4, EVR patients $(n=39)$ versus nonEVR patients $(n=21)$ are presented in Figures 3 and 4. Although the absolute counts of mature $\mathrm{T}$ cells were slightly lower in EVR than in non-EVR patients, there was no significant change in response to PegIFN/RBV therapy (Fig. 3a, $p>0.05$ ). In contrast, the percentages of mature $\mathrm{T}$ cells were slightly higher, but also with no significant change in response to the PegIFN/RBV therapy (Fig. $4 \mathrm{a}, p>0.05)$. As for the absolute counts of $\mathrm{T}$ helper cells, a continuous decline was detected after initiation of PegIFN/RBV therapy in EVR patients until 26 weeks, with a significant difference at 4 weeks of PegIFN/RBV therapy (Fig. 3b, $p<0.05$ ). As for the percentages of T helper cells, a significant difference between the 2 groups was detected at 4 and 13 weeks of PegIFN/RBV therapy (Fig. $4 \mathrm{~b}, p<$ 


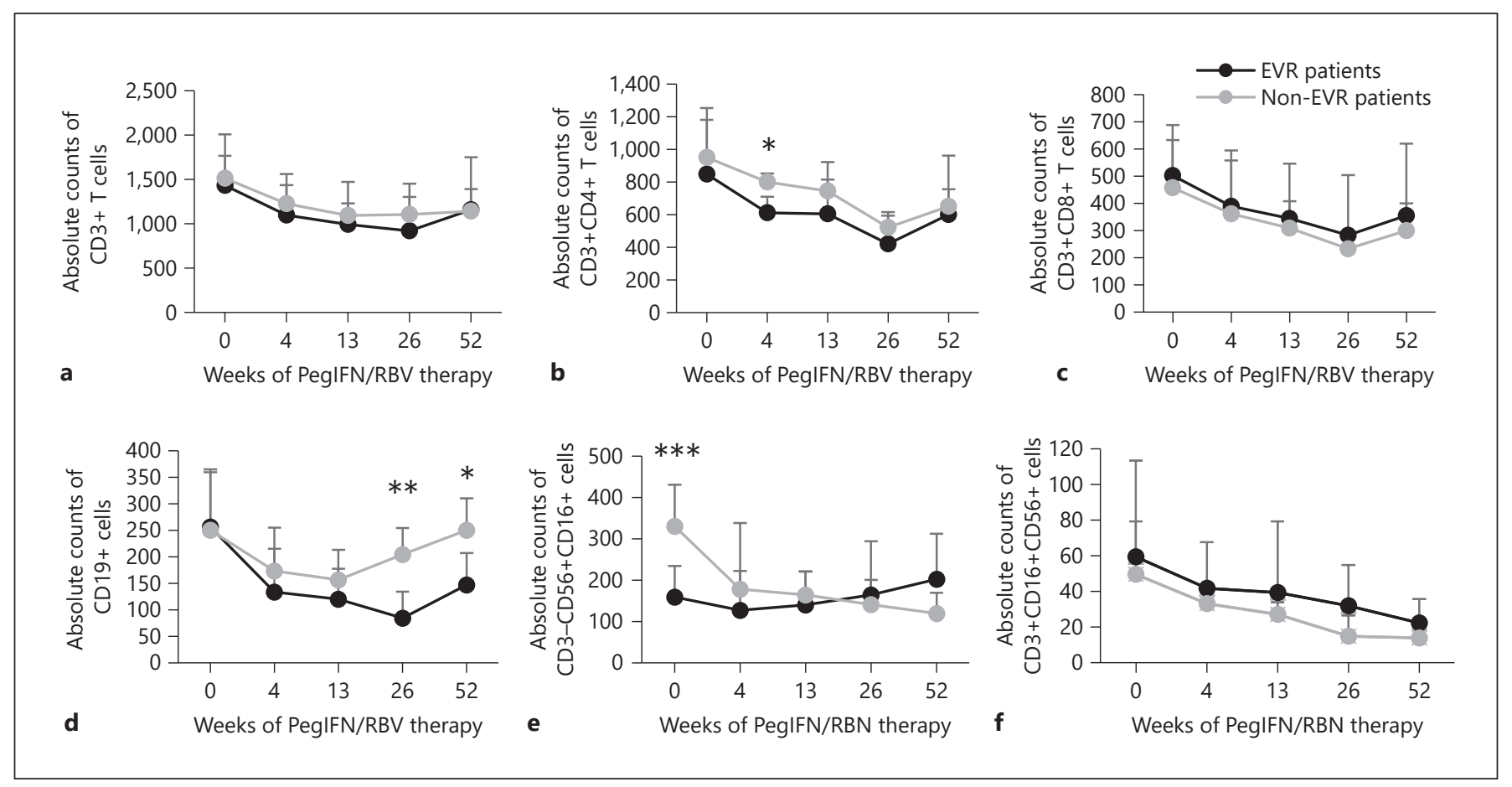

Fig. 3. Mean values for absolute counts for EVR and non-EVR patients. Mature T cells (a), T helper cells (b), T cytotoxic cells (c), B cells (d), NK cells (e), and NKT cells (f) at baseline values and during the course of PegIFN/ RBV therapy (at 4, 13, 26, and 52 weeks). Error bars illustrate the standard deviations. ${ }^{*} p<0.05,{ }^{* *} p<0.01$, ${ }^{* * *} p<0.001$ refer to the statistical differences among EVR and non-EVR patients. EVR, early virological response; NK, natural killer; NKT, natural killer/T; PegIFN/RBV, pegylated interferon- $\alpha$ and ribavirin.

0.05). Furthermore, the absolute counts of $\mathrm{T}$ cytotoxic cells were slightly higher in EVR patients after initiation of PegIFN/RBV therapy, with no significant difference (Fig. $3 c, p>0.05$ ). Also, higher mean values for the percentage of T cytotoxic cell were detected in EVR than in non-EVR patients, with significant differences at baseline and at 4 and 13 weeks after the initiation of PegIFN/RBV therapy (Fig. $4 c, p<0.01, p<0.01, p<0.05$ respectively). On the other hand, B cell absolute counts and percentages continued to show a decrease in EVR patients, with a significant decline at 26 and 52 weeks after the initiation of the PegIFN/RBV therapy (Fig. $3 \mathrm{~d}, p<0.01$ and $p<0.05$, respectively, and Fig. 4 d, $p<0.001$ ). The absolute counts and percentages of NK cells for EVR patients started with significantly lower values at baseline (Fig. 3e, 4 e, $p<0.001$ each). Then, after the initiation of the PegIFN/RBV therapy, they continued to increase but with no significant differences (Fig. 3e, 4e, $p>0.05$ ). As for the absolute counts of NKT cells, there was a decline over the weeks of PegIFN/RBV therapy for both groups of patients with no significant difference (Fig. 3f, $p>0.05$ ). Furthermore, per-

Immune Cell Subsets in Chronic HCV Patients centages of NKT cells for EVR in comparison with nonEVR patients were higher after the initiation of PegIFN/ RBV therapy, with a significant difference at 4 weeks, then it showed a sharp decrease at 52 weeks of therapy with no statistical difference (Fig. 4f, $p<0.05$ and $p>0.05$, respectively). Interestingly, the percentages of Treg cells revealed a remarkable decrease in EVR in comparison with nonEVR patients, with a highly significant difference at 4, 26, and 52 weeks after the initiation of PegIFN/RBV therapy (Fig. 4g, $p<0.001$ ). Also, the percentages of activated T cells for EVR in comparison with non-EVR patients showed a significant increase at baseline values, then the values increased for the non-EVR patients, with a significant difference between the 2 groups at 13 and 26 weeks after the initiation of PegIFN/RBV therapy (Fig. $4 \mathrm{~h}, p<$ $0.01)$. As for the T helper:T cytotoxic cells ratio, it was significantly lower for EVR than for non-EVR patients at baseline values (Fig. 4i, $p<0.01$ ). After the initiation of PegIFN/RBV therapy, it continued this way until 26 weeks, with a significant difference at 4 and 13 weeks (Fig. $4 \mathrm{i}, p<0.001$ and $p<0.05$, respectively). 


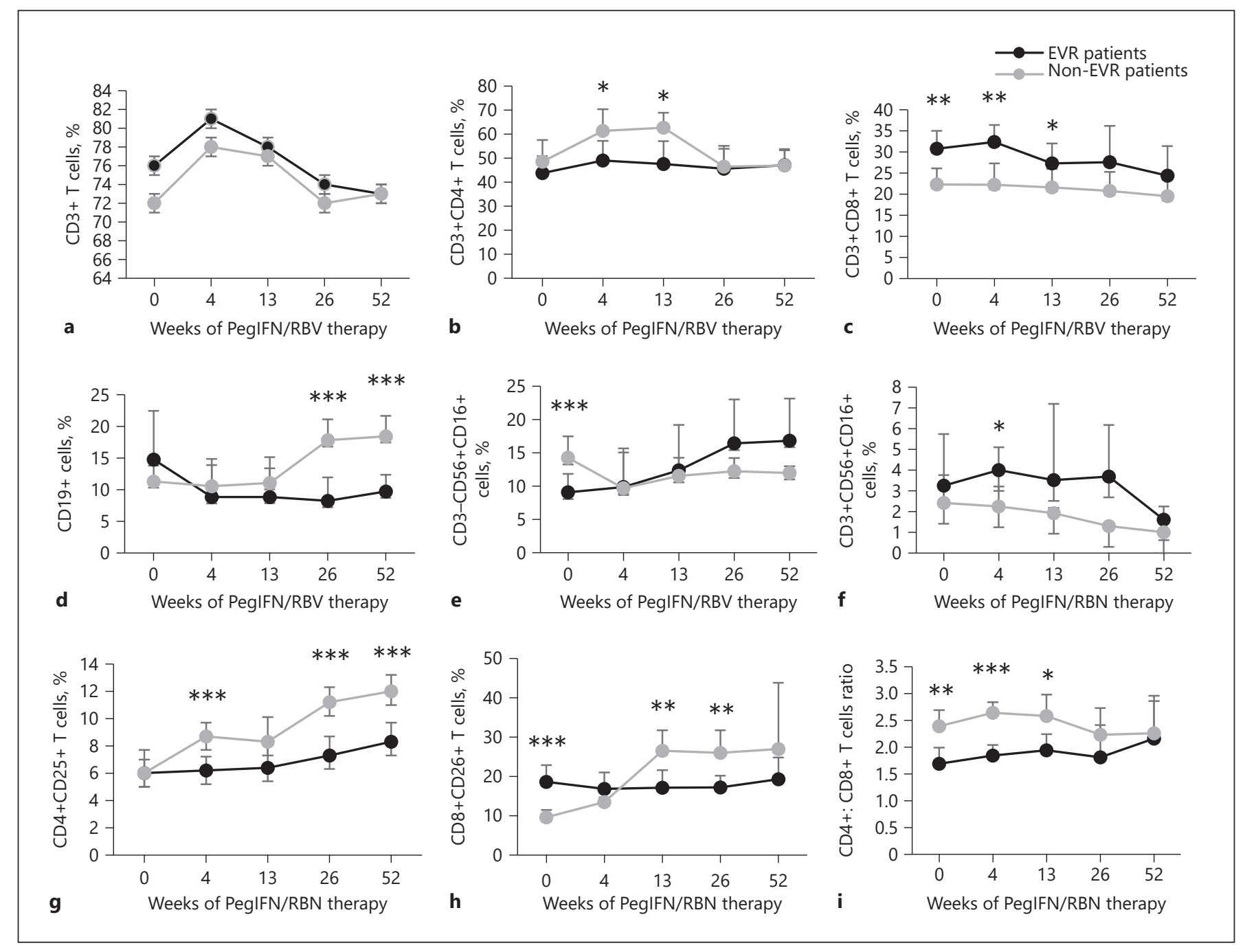

Fig. 4. Mean values for percentages for EVR and non-EVR patients. Mature T cells (a), T helper cells (b), T cytotoxic cells $(\mathbf{c})$, B cells $(\mathbf{d})$, NK cells $(\mathbf{e})$, NKT cells $(\mathbf{f})$, Treg cells $(\mathbf{g})$, activated T cells $(\mathbf{h})$, and CD4 ${ }^{+}: \mathrm{CD}^{+}$ratio (i) at baseline values and during the course of PegIFN/RBV therapy (at 4, 13, 26, and 52 weeks). Error bars illustrate the standard deviations. ${ }^{*} p<0.05,{ }^{* *} p<0.01,{ }^{* * *} p<0.001$ refer to the statistical differences among EVR and non-EVR patient. EVR, early virological response; NK, natural killer; NKT, natural killer/T; Treg, T regulatory; PegIFN/RBV, pegylated interferon- $\alpha$ and ribavirin.

\section{Discussion}

This study aimed at carrying out a comparative analysis of immune cell subsets in the peripheral blood of chronically $\mathrm{HCV}$-infected patients during the course of PegIFN/RBV therapy in an attempt to understand the mechanism of action of the therapy. To fulfill this objective, we measured the absolute counts and/or percentages of mature T, T helper, T cytotoxic, B, NK, NKT, Treg, T helper:T cytotoxic ratio, and activated $\mathrm{T}$ cells over a period of 52 weeks in EVR patients before and during
PegIFN/RBV therapy. EVR was used as a clinical marker to monitor the progress of treatment/disease.

We observed that the absolute counts and/or percentages of mature T, T cytotoxic, NKT, Treg, T activated, and $\mathrm{B}$ cells were significantly reduced in chronically HCVinfected patients when compared to HC. Earlier studies identified variations in the proportion of $\mathrm{T}$ subsets, NK, and NKT cells in peripheral blood of chronically HCVinfected patients at baseline values [8-11], which could indicate the importance of these immune cell subsets in the persistence of $\mathrm{HCV}$ infection. An interesting aspect of 
chronic HCV infection is the development of weak T helper and $\mathrm{T}$ cytotoxic responses caused either by a primary $\mathrm{T}$ cell failure or by $\mathrm{T}$ cell exhaustion [4]. Moreover, changes in the Thelper:T cytotoxic ratio may cause a failure in the coordination between them, which could result in chronic persistent infection [13]. The other interesting observation made in the present study is that the percentages of Treg cells in the HCV-infected patients were significantly lower when compared to $\mathrm{HC}$, which is inconsistent with a previous study [9]. Mechanisms of T cell dysfunction might include the action of Treg cells due to impaired priming of virus-specific $\mathrm{T}$ cells and suppression by inhibitory cytokines [14]. These variations in Treg cell proportion may play an essential role in $\mathrm{HCV}$ persistence $[9,11]$.

Earlier studies have reported low NK cell quantity and altered NK functions in chronic HCV infection $[2,8,15]$; these perturbations in levels may contribute to a failure to clear HCV infection. The reason for the decreased absolute count of NK and NKT cells in chronically HCV-infected patients is currently unidentified, although possible explanations may include increased death or turnover or reduced production of these cells [16].

The significant decrease in the absolute counts and/or the percentages of immune cell subsets in chronically $\mathrm{HCV}$-infected patients, when compared to $\mathrm{HC}$, may represent an immunomodulatory effect of $\mathrm{HCV}$ infection on these cell populations, as suggested previously [17]. Also, this imbalance in the immune cell subsets could facilitate the persistence of HCV infection [15]. It is also possible that this represents an immunological escape mechanism by HCV, which appears to survive in the presence of an impaired immune response [17].

Interestingly, we detected a significant increase in the percentages of T cytotoxic cells (at 4 and 13 weeks) in the EVR in comparison to non-EVR patients. On the other hand, the percentages of $\mathrm{T}$ helper cells (at 4 and 13 weeks), $\mathrm{T}$ activated cells (at 13 and 26 weeks), and T helper:T cytotoxic ratio (at 4 and 13 weeks) showed a significant decrease in EVR in comparison to non-EVR patients. In addition, when the absolute counts of T helper cells of the EVR and non-EVR patients were compared, the EVR patients showed a significant decrease after 4 weeks after the initiation of PegIFN/RBV therapy. This could be due to "immunological exhaustion" of circulating T helper cells. Some researchers suggest that the immune system tries to eradicate the HCV infection during the initial stages of infection and treatment. Subsequently, some functional responses might be damaged [18]. Although the exact effective mechanisms implemented by $\mathrm{T}$ cytotoxic cells to

Immune Cell Subsets in Chronic HCV Patients clear HCV still remain to be revealed, a previous study by Spangenberg et al. [19] found that a lasting and comprehensive $\mathrm{T}$ cytotoxic response is essential for effective elimination of HCV infection. A recent study indicated that antiviral IFN-free therapy-mediated restoration of $\mathrm{T}$ cytotoxic cells may restore $\mathrm{T}$ cytotoxic cell impaired function in chronically HCV-infected patients $[6,20]$. Another study showed that PegIFN/RBV therapy is associated with an enhanced HCV-specific cytotoxic T cell response, which leads to a positive correlation between the induction of PegIFN/RBV therapy and HCV-specific T cytotoxic responses in chronically $\mathrm{HCV}$-infected patients [21]. Therefore, we speculate that PegIFN/RBV therapy may associate with immune stimulation that could repair certain immune cell subsets by supporting clonal extension and cellular development [22] or by reducing $\mathrm{T}$ cell exhaustion by reducing viral load [23]. The functional restoration of these immune cell subsets might be considered as an early prognostic marker of the effective immune response [24]. Restoration of levels of $\mathrm{T}$ cytotoxic cells could be the initial step in the restoration of effector cell function that might happen alongside the PegIFN/ RBV therapy.

We detected a negative correlation between the percentages of Treg cells and HCV RNA at baseline. Such a correlation was not detected after treatment. Several studies have demonstrated a positive correlation between increased Treg cell counts and chronic HCV infection $[10,25,26]$; this discrepancy may be due to differences in study populations, as we compared genotype- 4 EVR and non-EVR patients. Cabrera et al. [10] and Sugimoto et al. [25] compared untreated, spontaneously recovered HCV subjects and chronically HCV-infected patients, whereas Ebinuma et al. [26] compared untreated HCV-infected and uninfected individuals. After the initiation of PegIFN/RBV therapy, the percentages of Treg cells showed a significant decrease in EVR in comparison to non-EVR patients at 4,26, and 52 weeks, which is consistent with a previous study [11]. This result may suggest a possible role for Treg cells in the virological response to PegIFN/RBV therapy. Hao et al. [11] reported that the frequency of Treg cells was reduced 4 weeks after the initiation of PegIFN/RBV therapy and continued to decrease during the follow-up period in subjects with rapid virological response. In contrast, another study revealed that effective PegIFN/RBV therapy is associated with an increase in Treg cells, with a slight recovery of the damaged immune response in nonresponder patients [7].

Interestingly, we observed a positive correlation between HCV viral load in EVR patients and the percent- 
ages of B cells 4 weeks after initiation of PegIFN/RBV therapy. However, the absolute counts of B cells as well as $\mathrm{B}$ cell percentages decreased significantly at 26 and 52 weeks in EVR patients after the initiation of PegIFN/RBV therapy. Amati et al. [27] described higher absolute counts of $B$ cells in poor responders than in responders at the end of the PegIFN/RBV therapy, which is similar to our obable to higher levels of anti-lactoferrin (LF) antibodies in nonresponders than in the responders, and that these autoantibodies might affect the antiviral activity of LF and block LF binding to LPS. Such interactions would obstruct the binding of LPS to LPS-binding protein, thus preventing LPS fixation to $\mathrm{CD} 14^{+}$, eventually leading to a reduced release of proinflammatory cytokines.

We also observed that the absolute counts and percentages of NK cells were continuously increased but with no significant difference between the EVR and non-EVR patients after the initiation of PegIFN/RBV therapy. This could be due to increased dynamism of NK cells [16]. He et al. [28] suggested that IFN- $\alpha$ enhances the expression of CD100 on NK cells, which plays an important role in promoting NK function in patients with chronic hepatitis C. On the other hand, we noted a significant increase in the percentages of NKT cells shortly after the initiation of PegIFN/RBV therapy, that is, at 4 weeks. The reason for this of NKT cells in the clearance of HCV infection in EVR in comparison to non-EVR patients, which led to the recovery of NKT cell population to normal proportions $[8,29]$. NKT cells could inhibit HCV replication via the secretion of IFN- $\gamma$, thus playing vital roles in antiviral defenses [4]; their antiviral activity has been shown to be associated with the consequence of acute HCV infection [3] and the efficacy of IFN- $\alpha$ treatment in chronically infected HCV patients [8, 29]. Interestingly, the activation of NKT cells by a-galactosylceramide, a novel synthetic glycolipid, has been shown to reduce HCV viral replication, as determined by reduction in viral load during chronic HCV infection in chimpanzees [30]. Thus, our findings suggest that stimulation of NKT cells by the PegIFN/RBV therapy may be necessary for the resolution of chronic HCV infection.

\section{Conclusion}

Our working hypothesis was that antiviral therapy in EVR patients leads to the production of effective immune cell subsets, which can aid in viral clearance during PegIFN/RBV therapy. Data presented in this study suggest servation. Amati et al. [27] suggested that this is attributincrease remains unclear, but it may reflect the importance

that chronic $\mathrm{HCV}$ infection has an immunomodulatory effect on immune cell subsets. Our results indicate that the enhancement of T cytotoxic and NKT cells and the reduction of B cells, Treg cells, and T activated cells by PegIFN/ RBV therapy may facilitate the restoration of an effective immune response leading to HCV resolution. Future studies should consider immunomodulatory therapeutic regimens that aim to enhance the antiviral response by improving the activity of cytotoxic T cells and NKT cells while inhibiting B cells and Treg cells in chronically HCV-infected patients, in particular non-EVR patients, for therapyrelated viral resolution. Limitations of this study include the fact that immune cell subsets were collected from peripheral blood samples; it would be more relevant to analyze these immune cell subsets in the local environment, that is, in the liver. Furthermore, the bulk of participants were genotype-4, and the availability of other genotypes would have allowed enhanced comparative results.

\section{Acknowledgements}

This study was funded by Kuwait University Research Sector Grant No. MI 02/13.

\section{Statement of Ethics}

Ethical approval was obtained from the Ethics Committee of the Health Science Center, Kuwait University, and the Ministry of Public Health. Each patient was interviewed and consented to enter the study. The patients were asked to sign a consent form after a verbal explanation by the physician soliciting their participation. All study procedures were performed in compliance with the ethical standards of the revised Declaration of Helsinki of 2008.

\section{Conflict of Interest Statement}

The authors declare that they have no conflicts of interest.

\section{References}

1 Chigbu DI, Loonawat R, Sehgal M, Patel D, Jain P. Hepatitis $C$ virus infection: host-virus interaction and mechanisms of viral persistence. Cells. 2019;8:376.

2 Golden-Mason L, Castelblanco N, O'Farrelly C, Rosen HR. Phenotypic and functional changes of cytotoxic CD56pos natural T cells determine outcome of acute hepatitis $\mathrm{C}$ virus infection. J Virol. 2007;81(17):9292-8.

3 Ye L, Wang X, Wang S, Wang Y, Song L, Hou $\mathrm{W}$, et al. CD56+ T cells inhibit hepatitis $\mathrm{C}$ virus replication in human hepatocytes. Hepatology. 2009;49(3):753-62. 
4 Lingala S, Ghany MG. Natural history of hepatitis C. Gastroenterol Clin North Am. 2015; 44(4):717-34

5 Santantonio T, Fasano M, Sagnelli E, Tundo P, Babudieri S, Fabris P, et al. Acute hepatitis C: a 24-week course of pegylated interferon $a-2 b$ versus a 12 -week course of pegylated interferon $a-2 b$ alone or with ribavirin. Hepatol. 2014;59:2101-9.

6 Martin B, Hennecke N, Lohmann V, Kayser A, Neumann-Haefelin C, Kukolj G, et al. Restoration of $\mathrm{HCV}$-specific $\mathrm{CD} 8+\mathrm{T}$ cell function by interferon-free therapy. J Hepatol. 2014;61(3):538-43.

7 Soldevila B, Alonso N, Martínez-Arconada MJ, Morillas RM, Planas R, Sanmartí AM, et al. A prospective study of T- and B-lymphocyte subpopulations, CD81 expression levels on B cells and regulatory CD4(+) CD25(+) CD127(low/-) FoxP3(+) $\mathrm{T}$ cells in patients with chronic HCV infection during pegylated interferon-alpha2a plus ribavirin treatment. J Viral Hepat. 2011;18(6):384-92.

8 Yamagiwa S, Matsuda Y, Ichida T, Honda Y, Takamura M, Sugahara S, et al. Sustained response to interferon-alpha plus ribavirin therapy for chronic hepatitis $\mathrm{C}$ is closely associated with increased dynamism of intrahepatic natural killer and natural killer T cells. Hepatol Res. 2008;38(7):664-72.

9 Wang JP, Zhang Y, Wei X, Li J, Nan XP, Yu HT, et al. Circulating toll-like receptor (TLR) 2, TLR4, and regulatory T cells in patients with chronic hepatitis C. APMIS. 2010; 118(4):261-70.

10 Cabrera R, Tu Z, Xu Y, Firpi RJ, Rosen HR, Liu C, et al. An immunomodulatory role for $\mathrm{CD} 4(+) \mathrm{CD} 25(+)$ regulatory $\mathrm{T}$ lymphocytes in hepatitis C virus infection. Hepatology. 2004; 40(5):1062-71.

11 Hao C, Zhou Y, He Y, Fan C, Sun L, Wei X, et al. Imbalance of regulatory $\mathrm{T}$ cells and $\mathrm{T}$ helper type 17 cells in patients with chronic hepatitis C. Immunology. 2014;143(4):531-8.

12 Deltenre P, Canva V, El Nady M, François C, Castelain S, Dharancy S, et al. A 2-log drop in viral load at 1 month is the best predictor of sustained response in HCV patients with normal ALT: a kinetic prospective study. J Viral Hepat. 2009;16(7):500-5.
13 Bengsch B, Seigel B, Ruhl M, Timm J, Kuntz $\mathrm{M}$, Blum HE, et al. Coexpression of PD-1, 2B4, CD160 and KLRG1 on exhausted HCVspecific CD8+ T cells is linked to antigen recognition and T cell differentiation. PLoS Pathog. 2010;6(6):e1000947.

14 Neumann-Haefelin C, Thimme R. Success and failure of virus-specific $\mathrm{T}$ cell responses in hepatitis C virus infection. Dig Dis. 2011; 29(4):416-22.

15 Lunemann S, Malone DF, Hengst J, Port K, Grabowski J, Deterding K, et al. Compromised function of natural killer cells in acute and chronic viral hepatitis. J Infect Dis. 2014; 209(9):1362-73.

16 Morishima C, Paschal DM, Wang CC, Yoshihara CS, Wood BL, Yeo AE, et al. Decreased $\mathrm{NK}$ cell frequency in chronic hepatitis $\mathrm{C}$ does not affect ex vivo cytolytic killing. Hepatology. 2006;43(3):573-80.

17 Dimitropoulou D, Karakantza M, Tsamandas AC, Mouzaki A, Theodorou G, Gogos CA. Tlymphocyte subsets in peripheral blood and liver tissue of patients with chronic hepatitis B and C. In Vivo. 2011;25(5):833-40.

18 Brenndörfer ED, Brass A, Karthe J, Ahlén G, Bode JG, Sällberg M. Cleavage of the T cell protein tyrosine phosphatase by the hepatitis $\mathrm{C}$ virus nonstructural $3 / 4 \mathrm{~A}$ protease induces a Th1 to Th2 shift reversible by ribavirin therapy. J Immunol. 2014;192(4):1671-80.

19 Spangenberg HC, Viazov S, Kersting N, Neumann-Haefelin C, McKinney D, Roggendorf $\mathrm{M}$, et al. Intrahepatic CD8+ T-cell failure during chronic hepatitis $\mathrm{C}$ virus infection. Hepatology. 2005;42(4):828-37.

20 Rehermann B, Bertoletti A. Immunological aspects of antiviral therapy of chronic hepatitis $B$ virus and hepatitis $C$ virus infections. Hepatology. 2015;61(2):712-21.

21 Larrubia JR, Lokhande MU, Moreno-Cubero E, García-Garzón S, Miquel J, Parra-Cid T, et al. HCV-specific CD8+ cell detection at week 12 of chronic hepatitis $\mathrm{C}$ treatment with PEGinterferon- $\alpha 2 b /$ ribavirin correlates with infection resolution. Cell Immunol. 2013; 286(1-2):31-8.

22 Velazquez VM, Uebelhoer LS, Thapa M, Ibegbu CC, Courtney C, Bosinger SE, et al. Systems biological analyses reveal the hepatitis $\mathrm{C}$ virus (HCV)-specific regulation of hematopoietic development. Hepatology. 2015;61(3): 843-56.

23 Webster GJ, Reignat S, Brown D, Ogg GS, Jones L, Seneviratne SL, et al. Longitudinal analysis of CD8+ T cells specific for structural and nonstructural hepatitis $B$ virus proteins in patients with chronic hepatitis B: implications for immunotherapy. J Virol. 2004; 78(11):5707-19.

24 Humphreys IS, von Delft A, Brown A, Hibbert L, Collier JD, Foster GR, et al. HCV genotype-3a T cell immunity: specificity, function and impact of therapy. Gut. 2012;61(11): 1589-99.

25 Sugimoto K, Ikeda F, Stadanlick J, Nunes FA, Alter HJ, Chang KM. Suppression of HCVspecific $\mathrm{T}$ cells without differential hierarchy demonstrated ex vivo in persistent HCV infection. Hepatology. 2003;38(6):1437-48.

26 Ebinuma H, Nakamoto N, Li Y, Price DA, Gostick E, Levine BL, et al. Identification and in vitro expansion of functional antigen-specific CD25+ FoxP3 + regulatory T cells in hepatitis $\mathrm{C}$ virus infection. J Virol. 2008;82(10): 5043-53.

27 Amati L, Cozzolongo R, Manghisi OG, Cuppone R, Pellegrino NM, Caccavo D, et al. The immune responsiveness in hepatitis $\mathrm{C}$ virus infected patients: effects of interferon-alpha/ ribavirin combined treatment on the lymphocyte response with special reference to $\mathrm{B}$ cells. Curr Pharm Des. 2004;10:2093-100.

28 He Y, Guo Y, Fan C, Lei Y, Zhou Y, Zhang M, et al. Interferon- $\alpha$-enhanced CD100/plexin$\mathrm{B} 1 / \mathrm{B} 2$ interactions promote natural killer cell functions in patients with chronic hepatitis $C$ virus infection. Front Immunol. 2017;8:1435.

29 Nakamura I, Asano T, Asabe S, Ando M, Sano T, Miyata Y, et al. Restoration of natural killer cell activity by pegylated interferon-alpha/ ribavirin therapy in chronic hepatitis $\mathrm{C} \mathrm{pa-}$ tient. Hepatol Res. 2015;45(1):107-12.

30 Mehta AS, Gu B, Conyers B, Ouzounov S, Wang L, Moriarty RM, et al. $a-\mathrm{Ga}-$ lactosylceramide and novel synthetic glycolipids directly induce the innate host defense pathway and have direct activity against hepatitis $\mathrm{B}$ and $\mathrm{C}$ viruses. Antimicrob Agents Chemother. 2004;48(6):2085-90.
Immune Cell Subsets in Chronic HCV Patients
Med Princ Pract 2021;30:168-177 